\title{
DO WE PRACTICE WHAT WE PREACH? EXPERIENCE OF WORKING DOCTOR MOTHERS REGARDING ORGANIZATION SUPPORT FOR BREASTFEEDING AT WORKPLACE
}

\section{Zeeshan Noor Shaikh', Jamil Ahmed Soomro ${ }^{2 \otimes}$, Wardah Ahmed ${ }^{3}$, Suhail Raza Shaikh ${ }^{4}$, Shahmeen Nazar ${ }^{5}$, Amir Ali Samnani ${ }^{4}$}

\begin{abstract}
OBJECTIVE: To assess breastfeeding support provided to urban working doctor mothers at their workplace.

METHODS: This cross-sectional study was carried out among four tertiary level urban hospitals of Pakistan, between January-June 2017. Through random sampling, 215 working female doctors who were breastfeeding (3-24 months) were included. Data was collected using structured questionnaire based upon "World Alliance for Breastfeeding in Action" guidelines. The data was analyzed using SPSS software version 24. Breastfeeding facilities at workplaces were taken as outcome variables.

RESULTS: Among non-physical facilities, $89 \%$ of the doctor mothers received at least 03 months fully paid maternity-leave, $15 \%$ received enough breastfeeding breaks, and almost $12 \%$ of the mothers were offered flexible-job and information with regards to breastfeeding support options at workplace (hospitals). Regarding physical facilities, breastfeeding corner and onsite nursery for childcare was accessible to $5 \%$ and $2.3 \%$ of doctor mothers. However, none of the hospitals supported mothers with refrigerator for storing mother's milk and breast milk pump. Additionally, statistically significant difference $(<0.00 \mathrm{I})$ was observed by type of employer (government or private) breastfeeding breaks, lactation corner, and fully paid maternity leave.
\end{abstract}

CONCLUSION: Enabling and supportive environment to working doctor mothers for breastfeeding at workplaces was missing in majority of the healthcare facilities. Female doctors having positive practical experience with solutions can be instrumental for their patients (working mother) in preventing early weaning.

KEY WORDS: Breastfeeding Facilities (MeSH); Working Mothers (MeSH); Physician Mothers (MeSH); Workplace Breastfeeding Support (MeSH)

THIS ARTICLE MAY BE CITED AS: Shaikh ZN, Soomro JA, Ahmed W, Shaikh SR, Nazar S, Samnani AA. Do we practice what we preach? Experience of working doctor mothers regarding organization support for breastfeeding at workplace. Khyber Med Univ J 2020;12(4): 315-20. DOI: I0.35845/kmuj.2020.196/9.

\section{INTRODUCTION}

$\mathrm{T}$ he promotion of breastfeeding is a major global health concern. It is widely reported that the breastfed children are healthier and have fewer sicknesses than non-breastfed children. ${ }^{1-5}$ In resource-poor countries the breastfeeding is a dream product, a window of opportunity that almost every mother and family could afford, yet circumstances often seem to conspire against the practice. ${ }^{6}$ Globally
I 59 million children are undernourished and half of all these children under five live in Asia and one third live in African countries. ${ }^{\text {? }}$

Exclusive breastfeeding for first six months of life of an infant is associated with 14 times reduced risk of death attributable to diarrhea and acute respiratory infection in comparison to a child who is not breastfed. Furthermore, it effect on individual's development, their future education,
I. School of Public Health, Dow University of Health Sciences, Karachi, Pakistan.

2. Department of Community Health Sciences, Muhammad Medical College, Mirpur Khas, Pakistan.

3. Department of Community Health \& Preventive Dentistry, Hamdard University, Karachi, Pakistan.

4. Nutrition Support Program Sindh, Pakistan.

5. APPNA Institute of Public Health, Jinnah Sindh Medical University, Karachi Email『: jamiljan197@hotmail.com

$\begin{array}{ll}\text { Date Submitted: } & \text { August 17, 2019 } \\ \text { Date Revised: } & \text { October 20, 2020 } \\ \text { Date Accepted: } & \text { October 23, 2020 }\end{array}$

labor productivity (earning potential) and ultimately effect on country's GDP.

According to recent Pakistan nutritional survey, the prevalence of malnutrition in kids under 5 years of age is very high, $40.2 \%$ are stunted and $17.7 \%$ suffer from wasting. ${ }^{9}$ Currently Pakistan faces second highest infant mortality in Asia after Afghanistan. ${ }^{10}$ Various studies have shown, drop in the percentage of infant mortality by breastfeeding up to recommended period. ${ }^{11,12}$ Within limited resources, in a developing country like Pakistan, the breastfeeding is a window of hope. The Pakistan demographic and health survey revealed the proportion of exclusive breastfeeding among infants under age of six months is approximately $38 \%$, furthermore, the survey has revealed linkages between working status of women and subsequent partial or complete discontinuation of breastfeeding. ${ }^{13}$

It is assumed that medical-counsels or bodies and hospitals would serve as a role model regarding provision of support to successfully combine breastfeeding with work; however, reality is challenging the assumption. A study accomplished in an academic 
TABLE I: BREASTFEEDING FACILITIES PROVIDED AT HEALTHCARE FACILITIES

\begin{tabular}{|c|c|c|}
\hline \multirow[b]{2}{*}{ Type of Breastfeeding Facilities (support) } & \multicolumn{2}{|c|}{ Mothers $(n=215)$} \\
\hline & $\begin{array}{c}\text { YES } \\
\mathbf{N}(\%)\end{array}$ & $\begin{array}{c}\text { NO } \\
\text { N (\%) }\end{array}$ \\
\hline \multicolumn{3}{|l|}{ Non-Physical facilities } \\
\hline At least 03 months full paid maternity leave & $192(89.3 \%)$ & $23(10.7 \%)$ \\
\hline Lighter job (task adjustment) & $26(12.1 \%)$ & $189(87.9 \%)$ \\
\hline Flexible time (breastfeeding breaks) & $33(15.3 \%)$ & $182(84.65 \%)$ \\
\hline $\begin{array}{l}\text { Employer provided information regarding } \\
\text { breastfeeding options }\end{array}$ & $25(11.6 \%)$ & $190(88.4 \%)$ \\
\hline \multicolumn{3}{|l|}{ Physical facilities } \\
\hline Separate room or corner for breastfeeding & II (5.I2\%) & $204(94.88 \%)$ \\
\hline Jobsite crèche (nursery for childcare) & $5(2.3 \%)$ & $210(97.7 \%)$ \\
\hline Breast milk pump & 0 & $215(100 \%)$ \\
\hline Refrigerator identified for storing breast milk & 0 & $215(100 \%)$ \\
\hline
\end{tabular}

TABLE II: BREASTFEEDING FACILITIES COMPARISON BETWEEN PRIVATE AND GOVERNMENT HOSPITALS

\begin{tabular}{|c|c|c|c|c|}
\hline Workplace Breastfeeding Facilities & $\begin{array}{c}\text { Government } \\
\begin{array}{c}(n=109) \\
N(\%)\end{array}\end{array}$ & $\begin{array}{c}\text { Private } \\
(n=106) \\
N(\%)\end{array}$ & $\begin{array}{c}\text { Total } \\
(n=2 \mid 5) \\
N(\%)\end{array}$ & p-value \\
\hline $\begin{array}{l}\text { Flexible time (Breastfeeding breaks) } \\
\text { Yes }\end{array}$ & 25 (23\%) & $8(7.5 \%)$ & 33 (I5.3\%) & .001 \\
\hline $\begin{array}{l}\text { Separate room or corner for } \\
\text { breastfeeding Yes }\end{array}$ & $9(8.3 \%)$ & $2(1.9 \%)$ & II (5.1\%) & .003 \\
\hline $\begin{array}{l}\text { Separate refrigerator to store breast } \\
\text { milk Yes }\end{array}$ & 0 & 0 & 0 & - \\
\hline $\begin{array}{l}\text { Breast milk pump } \\
\text { Yes }\end{array}$ & 0 & 0 & 0 & - \\
\hline $\begin{array}{l}\text { Jobsite crèche (nursery for childcare) } \\
\text { Yes }\end{array}$ & $4(3.7 \%)$ & I (0.9\%) & $5(2.3 \%)$ & .193 \\
\hline $\begin{array}{l}\text { Fully paid maternity leave } \\
\text { Yes }\end{array}$ & $109(100 \%)$ & $83(78.3 \%)$ & $192(89 \%)$ & .0001 \\
\hline $\begin{array}{l}\text { Task adjustment (lighter job) } \\
\text { Yes }\end{array}$ & $18(16.5 \%)$ & $8(7.5 \%)$ & $26(12 \%)$ & 0.34 \\
\hline $\begin{array}{l}\text { Information regarding breastfeeding } \\
\text { options Yes }\end{array}$ & $16(14.7 \%)$ & $9(8.5 \%)$ & 25 (I I.6\%) & .114 \\
\hline
\end{tabular}

setting in the USA revealed that I/4th of women workers failed to receive lactation corner, while majority of mothers criticized about insufficient maternity leave; $30 \%$ of mothers could not sustain exclusive breastfeeding for 6 months; around $92 \%$ females indicated that their bad personal experience may make it problematic for them to guide clients for breastfeeding support. ${ }^{14}$ The female doctors are at the forefront of encouraging mothers to achieve recommended breastfeeding target, yet female doctor mothers face substantial barriers in achieving their own breastfeeding goals. ${ }^{15}$

The current study design based on the guidelines of Global Alliance for Breastfeeding (WABA) in action ${ }^{16}$ aims to understand the status of breastfeeding support provided at workplace to female doctors in urban settings of Pakistan.

\section{METHODS}

This was a cross sectional survey approved by Ethical Review Committee (ERC) of Dow University of Health
Sciences, Karachi, Pakistan. Informed written consent was taken from the participants before the start of the interview. The sample size was calculated $(n=209)$ with Open Epi. ${ }^{17}$ The sample size was increased to $\mathrm{n}=228$ (57 respondents from each of four hospital) and we were able to collect data from 215 female doctors. The study was done over a period of six months from January 2017 to June 2017 at four major tertiary care Hospitals of an urban city. Registration of healthcare facility with Pakistan Medical and Dental Council (PMDC) was considered for studying breastfeeding services provided to female doctors. Equal number of female doctors were taken from all hospitals using simple random sampling, the list of female doctors was taken from medical superintendent of the concerned hospital. The urban city represents virtually every social class and ethnic group in Pakistan. The two third of the females in urban areas of Pakistan works in schools and hospitals. However, due to limited time and resources we only considered medics (female doctors) who works in tertiary care hospitals. The structured questionnaire was designed using World Alliance for breastfeeding Action guidelines. ${ }^{16}$ Questionnaire was piloted on six respondents (female doctors) from non-study setting area. Changes were made according to the context in the style and language of the questionnaire to make it comprehensible for the respondents. The questionnaire includes two parts. First section consisted of information regarding socio-demographic characteristics of the workplaces such as type of organization (Private or Government), name of the organization and locality. The project focused on assessment of lactation support provided by employer, therefore, to avoid expected ethical issues, the identifiable information with regards to working mother such as respondent's name, address, and other personnel information were not included. The second part of the questionnaire enquired information regarding the provision of breastfeeding support such as breastfeeding corner, breastfeeding breaks, jobsite crèche (nursery), place 


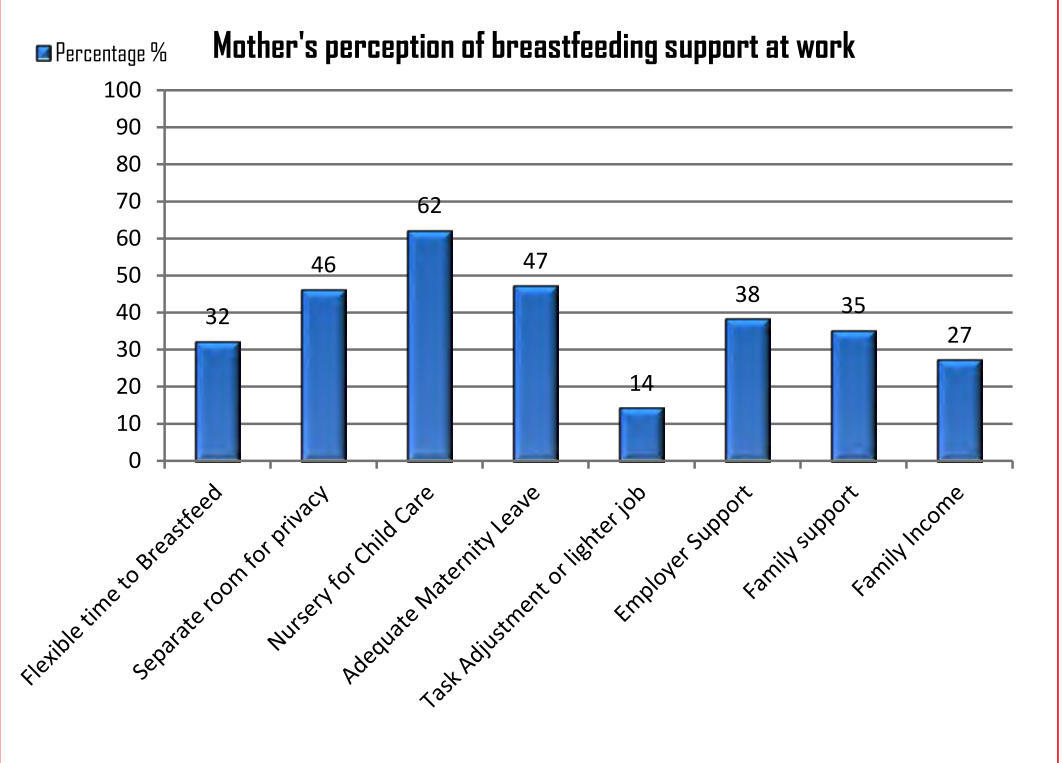

Figure I: Workplace breastfeeding facilities provided to the working doctor mothers

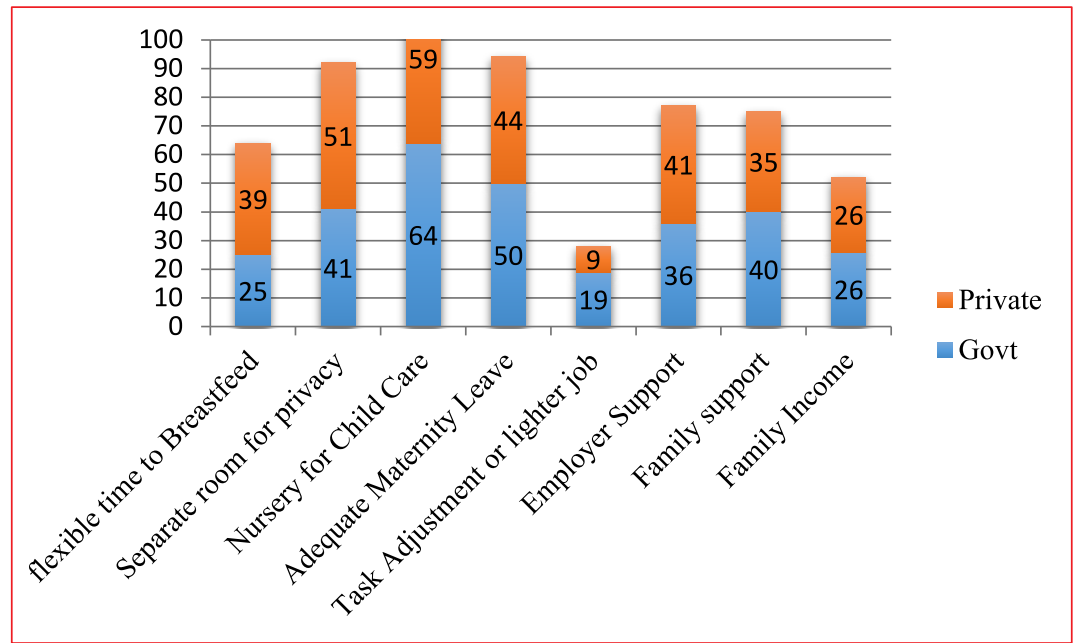

Figure 2: Comparisons of mothers' importance to lactation support areas in private and government sectors

for safe storage of mothers milk, provision of breastfeeding option to mothers, paid maternity leave, lighter job. The working mother (female doctor) was thought the most suitable person in a workplace to know about the availability and accessibility to workplace breastfeeding services. Participants were female doctors and specialist who delivered baby in last three to twenty-four months and initiated breastfeeding before the start of the survey. Female physicians with a baby who was unable to breastfeed due to any illness and twins were excluded from our study. Two female enumerators were trained before start of the data collection in order to maintain the reliability of the research instrument. Principal investigator accompanied and regularly monitored the process of data collection. The Data was analyzed using SPSS-Software. All our data was in categorical format, hence type of breastfeeding facilities, type of organization was presented in frequencies and percentages. Chi Square test was applied to all categorical variables for example type of workplace and provision of breastfeeding facilities.

\section{RESULTS}

The data was collected from 04 Tertiary care Hospitals of an urban city of Pakistan. The sites included were Baqai Medical University, Hospital ( $n=50)$, AlTibri Medical College Hospital $(n=56)$, Civil Hospital Karachi (CHK) $(n=53)$ and Lyari General Hospital $(n=56)$, Karachi, Pakistan. The questionnaire was completed by 215 mothers. The types of organizations were almost equal; private $(n=106)$ compared to government $(n=109)$ sites.

All the departments in two workplaces (Baqai Medical University, Hospital and Al-Tibri Medical College Hospital) were within one building, hence, task adjustment option to bring mother close to her home was not practicable. However, Civil Hospital Karachi (CHK) and Lyari General Hospital were relocating few mothers to their allied institutes. Overall, task and shift adjustment to ease workload of breastfeeding mothers was observed in $12 \%$ of workplaces. Among other nonphysical breastfeeding facilities, the fully paid three months maternity leave as per national guidelines was offered to most female doctors. Non-physical breastfeeding facilities include a private and clean place to breastfeed their baby, onsite childcare nursery, breast milk pump and refrigerator for storing breast milk.

In order to see the difference in public and private sector hospitals with regards to breastfeeding facilities, the descriptive analysis showed statistically significant difference in available breastfeeding facilities to mother working in government vs private such as: almost one out of three mothers working in government vs in private said that they were provided regular breaks for breastfeeding of at least one hour in a shift of 6-8 hours. Similarly, higher number of mothers in government hospitals reported availing breastfeeding corner (separate room) compared to the mothers working in private sector hospitals (Government vs Private; $8.3 \%$ vs $1.9 \% p=0.003)$ as evident from the p-value. Furthermore, fully paid three months maternity leave was extended to all 
women working in government sector, which was not the case in private sector.

Provision/ availability of nursey for childcare, tasks adjustment and information provision were statistically insignificant and had no influence on breastfeeding practices. Ironically, none of the hospitals provided refrigerator (for breast milk storage) and break milk pump.

In order to know the female doctors personal experience on breastfeeding support at work, semi structured questionnaire was given to working doctor mothers to define possible areas of supporting breastfeeding practices when it comes to work. Two third of women respondents believe that onsite nursery room (for childcare) was highly central to accomplish breastfeeding responsibility at fifty per cent of participants argued adequate paid maternity leave and breastfeeding corner are central in initiating and sustaining breastfeeding at work. Others claimed family support (37\%) and sufficient breastfeeding breaks (27\%) as important factors regarding breastfeeding at workplaces. Fewer women also emphasized employer's support for breastfeeding in workplaces.

Figure 2 illustrates the comparisons of mothers' understanding of lactation support in private and government sectors. There is not major difference of opinion except in case of flexibility of time for breastfeeding. Private sector employees emphasized more on time breaks as compared to government employees. This is understandable considering the difference of work environment of private and government sector.

\section{DISCUSSION}

Assessment of breastfeeding facilities offered to working mother doctors was done in the study. We established that the workplaces (hospitals) were mostly not supported by the employers with regards to breastfeeding support in the light of international labour by-laws and a world alliance for breastfeeding action guidelines. ${ }^{16} \mathrm{~A}$ substantial difference was observed between government vs private hospitals in the areas of breastfeeding breaks, breastfeeding corner, paid maternity leave.

Our findings showed, $15.3 \%$ of the respondents claimed to get sufficient breaks to breastfeed baby or express breast milk for later use. Our results were almost similar to the study in Hong Kong (I \%). ${ }^{18}$ Another study had reported the global rate of exclusive breastfeeding among infants was around $9 \%$ better in countries that assured frequent breastfeeding breaks (fully paid) during work and vice versa. ${ }^{19}$ Hirani and colleagues, also instituted that the flexible job allow working women to sustain breastfeeding for longer duration while employed. ${ }^{20}$ In a Australian based study, researchers discovered that $16 \%$ of organizations were providing paid breastfeeding breaks. ${ }^{21}$ It has been widely reported that flexibility in working time offered to physician mothers for breastfeeding is critical to maintain breastfeeding at work. ${ }^{4,22-25}$ Offering breastfeeding breaks to mothers for lactation would reduce the job stress. ${ }^{21,24,26}$ Though, our results were not consistent with many of similar kind of studies in the west, because of the onsite lactation programs, breastfeeding policies, and other support provided to women through knowledge, schooling and support in those states. ${ }^{1.5,24}$ Pakistan had not been able to develop any policy regarding allocating flexible time for breastfeeding breaks at worksite. ${ }^{27,28}$ The ILO 2014 report stated that, 136 out of I 83 (7I\%) countries globally had a policy for offering mothers with sufficient breaks to lactate their baby at-least up to six months. ${ }^{29}$

Accessibility to a separate room, refrigerator, breast milk pump allowing women worker to retain confidence and motivate them to run-through breastfeeding. ${ }^{20,29}$

Among physical facilities, the study reported that less than $5 \%$ workplaces have allocated breastfeeding corner for working mothers, while only $2 \%$ hospitals have earmarked a space (nursery) for daycare. The results are overlapping with earlier studies ${ }^{18,30}$ and inconsistent with the studies by Bai YK, et al. which reported $80 \% .^{14}$ The big difference is possibly due to the existence of programs, guidelines and information provided to the working females, through appropriate consultants in those settings, which is not there in our study population. Our Study sheds further light that $89 \%$ of the women were offered fully paid maternity leave for minimum three months, virtually similar to the researches done in other settings $(93 \%) .{ }^{23}$ Inadequate maternity leaves either force mothers to give away their work, resulting in significant financial damage in their income in the most productive period of their life, or compe them to start work too early, leading to adverse effects on both mother and baby health.' Almost 12\% of the female doctors in our study had stated to get information from their head of department or medical superintendent about breastfeeding options (possibilities) while resuming work. Our study findings are somehow similar to the study by Weber $\mathrm{D}$, et al. ${ }^{21} \mathrm{~A}$ significant difference $(<.00 \mathrm{I})$ was reported between public and private hospitals with regards to fully paid maternity leave, breastfeeding breaks, and allocation of corner for breastfeeding, resembles with the studies undertaken by Dodgson JE, et al. and Weber D, et al. ${ }^{18,21}$

Physician mothers working in the public hospitals in Pakistan, likely to have better breastfeeding backing compared to the private sector hospitals, possibly due to the following reasons.

The public hospitals are state owned; therefore, they are more likely to follow national guidelines on maternity protection. Secondly, the private hospitals see breastfeeding as women personnel issue. Thirdly, supporting breastfeeding cost money and resources which private hospital owner see as wastage of their money and resources, contrary to this government employer feels nothing going from their pocket, since the overall authority (financial, hiring etc.) is government. Lastly, the government sector is more likely to implement policies with regards to breastfeeding at work, compared to private hospitals. ${ }^{1.6,15}$ Stand by to the needs and wants of physician mothers is best accomplished as soon as administrative structure exist with clearcut guidelines to address breastfeeding related issues. Without these policy guidelines, the employer will not be ready to support breastfeeding practices at work.

The mother's perception was also evaluated in our study using initially openended questionnaire, which was structured later based on common responses, to know how mothers perceives breastfeeding support at work. 
The commonly reported breastfeeding facilities by mothers in our research were: onsite crèche or nursery for child care $(62 \%)$, sufficient maternity leave $(47 \%)$, breastfeeding corner (separate room) for maintaining privacy at work (46\%), proper support from employer, adequate breastfeeding breaks to breastfeed or express milk for later use, family support and family income etc., which are extensively described in earlier studies. ${ }^{5,20,27}$

The minor factors stated by Physician mothers that help instituting breastfeeding at work in our study were task adjustment, family income, and family support. Similar to the studies by Hirani et al and different from the studies by Dodgson JE, et al. and Weber $D$, et al. who described family income and support as the main decisive factor effecting breastfeeding at work. ${ }^{18,21}$ The variation could possibly due to priority of mothers, diverse study population and methodological issues.

\section{STRENGTHS AND LIMITATIONS}

This is a first kind of its study in Pakistan that focused the Physician mothers of urban tertiary care hospitals only, with a large random sample. We only consider working mothers (doctors), who have their baby's age below 2 years at the time of interview and had started breastfeeding in order to avoid recall bias. The mix methods would have been used to get deeper understanding of the mother perceptive of workplace breastfeeding facilities. Since we only considered urban region of Pakistan whereas, the study findings cannot be generalized to female physicians working in rural areas of Pakistan. We only chose tertiary hospitals registered with PMDC [currently renamed as "Pakistan Medical Commission (PMC]; however, small hospital \& health clinics were not taken into the account, may have influenced the external and internal validity of our study.

\section{CONCLUSION}

Generally, a common working woman relates to working doctor mother when it comes to breastfeeding in workplaces. When working doctor mothers face difficult and inadequate support at workplace for breastfeeding, then, how will they practice what they are preaching. Our study findings indicated that most of the workplaces (hospitals) were deprived of the facilities in the light of WABA to support physician mothers to be able to combine breastfeeding with job. Breastfeeding support at workplaces such as provision of refrigerator for breast milk storage, tasks and location adjustment, breastfeeding corner, flexibility of time and breastfeeding breaks play crucial role in continuation of breastfeeding in workplaces. An enabling and supportive environment may be provided to working mother doctors to give them confidence, credibility and strength to practice and preach breastfeeding.

\section{REFERENCES}

I. Cisco J. Who Supports Breastfeeding Mothers? Hum Nat 2017;28(2):23153. DOI: $10.1007 / \mathrm{s}|2| 10-017-9286-$ $y$.

2. Rollins NC, Bhandari N, Hajeebhoy N, Horton S, Lutter CK, Martines JC, et al. Why invest, and what it will take to improve breastfeeding practices? Lancet 2016;387:49|-504. DOI: 10.1016/s0140-6736(I5)01044-2.

3. Schanler RJ, Krebs NF, Mass SB. Breastfeeding handbook for physicians. 2nd Edition. USA. American Academy of Pediatrics; 2013.

4. Weiner L. From working girl to working mother: The female labor force in the United States, 1820-1980: UNC Press Books 2016;90(5): I-200. DOI: $10.2307 / 18598 \mid 8$.

5. World Health Organization. WHO technical brief: preventing HIV during pregnancy and breastfeeding in the context of PrEP: World Health Organization 2017:1-16. [Accessed on August 10, 2019]. Available from URL: https://www.who.int/hiv/pub/ toolkits/prep-preventing-hiv-duringpregnancy/en/

6. Brown C, Dodds L, Legge A, Bryanton J, Semenic $S$. Factors influencing the reasons why mothers stop breastfeeding. Can J Public Health 2014;105:179-85. DOI: I0.17269/ cjph. 105.4244 .

7. Domenico DM, Jones KH. Career aspirations of women in the 20th century. J Career Tech Edu 2007;22 (2):I-7. DOI: $10.2106 \mathrm{I} /$ jcte.v22i2. 430.

8. Hameed N, AAI S, Narchi H. Maternal factors hindering successful breastfeeding in Al Ain city, United
Arab Emirates. J Women Health Care 2014;4(I):I-4. DOI: 10.4I72/21670420.1000220

9. Government of Pakistan, UNICEF. National Nutrition survey 2018: Key finding report. June 2019. [Accessed on: August 10, 2019]. Available from URL: https://www.unicef.org/ pakistan/media/ I95I/file/Final\%20Ke y\%20Findings\%20Report\%2020। 9 . pdf.

10. Van Deursen B, Lenglet A, Ariti C, Hussain B, Kaarstan Jaap, Roggeveen $\mathrm{H}$, et al. Risks and seasonal pattern for mortality among hospitalized infants in a conflict-affected area of Pakistan, 2013-2016. A retrospective chart review. FI000Res 2019;8:I-13. DOI: I0. I2688/fI 000research. I 9547.I.

I I. Bahl R, Martines J, Victora C. Evidence on the long-term effects of breastfeeding. Geneva: World Health Organization 2007:I-57. DOI: ISBN 9789241595230 .

12. Lawrence RA, Lawrence RM. Breastfeeding: a guide for the medical professional: Elsev Health Sci 2015: I992. ISBN: 9780323394208.

13. Neville MC. Anatomy and physiology of lactation. Ped Clin of North Am 2001;48: 13-34. DOI: 10.1016/500313955(05)70283-2.

14. Bai YK, Gaits SI, Wunderlich SM. Workplace lactation support by $\mathrm{New}$ Jersey employers following US reasonable break time for nursing mothers law. J Hum Lact 20 I 5;31:7680. DOI: $10.1|77 / 08903344| 455$ 4620.

15. Christopher K. Breastfeeding perceptions and attitudes: the effect of race/ethnicity and cultural background. Soc Today 20 I 2; 10 (2).

16. World Alliance for Breastfeeding Action.(WABA). Key elements of maternity protection at work, Maternity Protection Campaigns kit. Section 2 2012:1-8. [Accessed on August I0, 2019]. Available from URL: http://waba.org.my/v3/wpcontent/uploads/20 I 8/08/2-KeyElements-of-Maternity-Protectionat-Work.pdf.

17. Dean AG, Sullivan KM, Soe MM. OpenEpi: Open Source Epidemiologic Statistics for Public Health, Version 3.0I. Updated 2013/04/06. [Accessed on: August I0, 
2019]. Available from URL: https://www.openepi.com/Menu/OE Menu.htm

18. Dodgson JE, Chee YO, Yap TS. Workplace breastfeeding support for hospital employees. J Adv Nurs 2004;47:9|-100. DOI: 10.1III/j. 1365-2648.2004.03070.x.

19. Heymann J, Raub A, Earle A. Breastfeeding policy: a globally comparative analysis. Bull World Health Organization 2013;91:398406. DOI: 10.247|/blt. 12.109363.

20. Hirani SAA, Karmaliani R. The experiences of urban, professional women when combining breastfeeding with paid employment in Karachi, Pakistan: A qualitative study. Women Birth 2013;26: 147-5I. DOI: 10.10I6/j.wombi.20I2.10.007.

21. Weber D, Janson A, Nolan M, Wen LM, Rissel C. Female employees' perceptions of organisational support for breastfeeding at work: findings from an Australian health service workplace. Inter Breastfeed J 201I;6(19):2-8. DOI: 10.1186/17464358-6-19.

22. World Health Organization. UNICEF. Global strategy for infant and young child feeding: World Health
Organization 2003:I-37. ISBN: 9241562218. [Accessed on: August 10, 2019]. Available from URL: https://apps.who.int/iris/bitstream/ha ndle/ I0665/42590/924 I5622 I8.pdf;js essionid $=48693$ EB 680 I C08297A20 $F C 847 B 33 D 033$ ? sequence $=1$

23. Simmie E. Breastfeeding: different ethnic background, different perceptions? Br J Midwif 2006; I4(I): 20-26. DOI: I0.12968/bjom.2006. 14.1.20256.

24. Tsai S-Y. Employee perception of breastfeeding-friendly support and benefits of breastfeeding as a predictor of intention to use breastpumping breaks after returning to work among employed mothers. Breastfeed Med 2014;9:16-23. DOI: 10.1089/bfm.2013.0082.

25. Victora CG, Bahl R, Barros AJ, Franca GVA, Horton S, Krasevec J, et al. Breastfeeding in the 2 Ist century: epidemiology, mechanisms, and lifelong effect. Lancet 2016;387:47590. DOI: $10.1016 / \mathrm{s} 0140-6736$ (I5) 01024-7.

26. Svendby HR, Løland BF, Omtvedt M, Holmsen ST, Lagerløv P. Norwegian general practitioners' knowledge and beliefs about breastfeeding, and their self-rated ability as breastfeeding counsellor. Scand J Prim Health Care 2016;34(2):I22-9. DOI: 10.3109/ 02813432.2016 .1160632

27. Soomro J, Shaikh Z, Bijarani S, Saheer T. Factors affecting breastfeeding practices among working women in Pakistan. East Mediterr Health J 20I 6;22(I I):8I0-6. DOI: $10.26719 / 2016.22 .11 .810$.

28. Hill EJ. Work-family facilitation and conflict, working fathers and mothers, work-family stressors and support. Fam Issues 2005;26:793-819. DOI: https://doi.org/10.1 I77/01925।3×05 277542.

29. Atabay E, Moreno G, Nandi A, Kranz G, Vincent I, Assi TM, et al. Facilitating working mothers' ability to breastfeed: global trends in guaranteeing breastfeeding breaks at work, 1995-20I4. J Hum Lact 20I5;3I(I):8I-8. DOI: 10.1177/ $08903344 \mid 4554806$.

30. Amin RM, Said ZM, Sutan R, Shah SA, Darus A, Shamsuddin K. Work related determinants of breastfeeding discontinuation among employed mothers in Malaysia. Int Breast 20II;6(4):I-6. DOI: 10.1I86/1746 4358-6-4.

\section{AUTHORS' CONTRIBUTIONS}

Following authors have made substantial contributions to the manuscript as under:

ZNS: Study design, analysis and interpretation of data, drafting the manuscript, approval of the final version to be published

JAS \& WA : Acquisition of data, critical revision, approval of the final version to be published

SRS \& SN: Acquisition, analysis and interpretation of data, drafting the manuscript, approval of the final version to be published

AAS: Acquisition of data, critical revision, approval of the final version to be published

Authors agree to be accountable for all aspects of the work in ensuring that questions related to the accuracy or integrity of any part of the work are appropriately investigated and resolved.

\begin{tabular}{|c|}
\hline CONFLICT OF INTEREST \\
Authors declared no conflict of interest \\
GRANT SUPPORT AND FINANCIAL DISCLOSURE \\
NIL
\end{tabular}

\section{DATA SHARING STATEMENT}

The data that support the findings of this study are available from the corresponding author upon reasonable request.

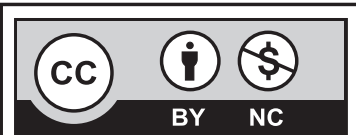

This is an Open Access article distributed under the terms of the Creative Commons Attribution-Non Commercial 2.0 Generic License.
KMUJ web address: www.kmuj.kmu.edu.pk

Email address: kmuj@kmu.edu.pk 